Como citar este artigo:

ARMENTA DEU, Teresa. Debido proceso, sistemas y reforma del proceso penal. Revista Brasileira de Direito Processual Penal, Porto Alegre, vol. 1,

n. 1, p. 121-139, 2015. http://dx.doi.org/10.22197/rbdpp.v1i1.7

\title{
DEBIDO PROCESO, SISTEMAS Y REFORMA DEL
} PROCESO PENAL

Teresa Armenta Deu ${ }^{1}$

http://dx.doi.org/10.22197/rbdpp.v1i1.7

\section{RESUMEN}

Este artículo se propone examinar los modelos de procesos penales de los movimientos de reforma que se establecieron en las últimas décadas del siglo XX, en los países iberoamericanos. Para ello, primero se enfatiza las características históricas de cada sistema, poniendo de relieve la importancia de no confundir el acusatorio con el adversarial, rechazando la coincidencia entre los sistemas actuales y mixto inquisitivo histórico. Apoya la importancia de la igualdad de armas y e del contradictoria en la búsqueda de un equilibrio entre los modelos de procedimiento.

PALABRAS CLAVE: Derecho Procesal Comparado. Sistemas Procesales. Adversarial. Inquisitivo. Acusatorio.

\section{ABSTRACT}

This article proposes to examine the criminal procedural models from reform movements that in the last decades of the twentieth century settled in Iberoamerican countries. First establishes the historical features of each system, highlights the importance of not confusing with the adversarial accusatory, rejects the equiparation between mixed current systems and historical inquisitive, and supports the importance of equality of arms and contradictory in the search for a balance between procedural models.

KEYWORDS: Compared Criminal Procedural Law. Procedural Systems. Adversarial. Inquisitive. Accusatory.

Catedrática de Derecho Procesal, UdG; Directora del CEAPJ. 


\section{Del pasado próximo a la actualidad: situaciones e ideas de partida $^{2}$}

Las postrimerías del siglo XXhan sido testigo de una auténtica convulsión en el ámbito de la justicia penal. Desde finales de los ochenta en Europa y principios de los noventa en Iberoamérica la gran mayoría de los códigos procesales penales han sido objeto de reformas totales que han supuesto mayoritariamente un cambio de paradigma en la orientación del modelo procesal.

Las razones son múltiples y van desde la legítima búsqueda de un modelo mejor hasta la innegable influencia de países con mayor peso cultural y/o económico que han ido componiendo un cuerpo de intelectuales formados en sus aulas y una decidida política de agencias internacionales, mayoritariamente norteamericanas, que han efectuado durante décadas inversiones millonarias en países de su ámbito de influencia. ${ }^{3}$

\section{La apelación al acusatorio}

En todos los códigos reformados, la apelación al "nomen" de los sistemasse ha convertido en un clásico, de manera que, con independencia de su carácter parcial o más amplio, todos repiten la consabida apelación a las bondades indiscutibles del sistema acusatorio o adversativo, a modo de invocación que sin más explicaciones cierra cualquier juicio desfavorable en torno a su necesidad, o a sus posible desventajas.

Así, en muchas ocasiones, no sólo se incurre en errores de significado graves sino, lo que es peor, se impide, consciente o inconscientemente, todo juicio crítico sobre la incidencia de la reforma en el conjunto del sistema de justicia, obviando, tantolo acaecido en otros ordenamientos donde se ha venido aplicando desde hace tiempo, como el conjunto de circunstancias sociales, políticas e institucionales al que se han ido incorporado reformas asimilables.

\section{La inexistencia de un modelo perfecto}

No existen modelos que salvaguarden la ortodoxia de ningún sistema, ni ninguno de los vigentes satisfaría hoy en día las exigencias del "proceso debido". Aseveración que no debe conducir al desánimo y menos aún a una huida del proceso, cuyo altísimo precio es larenuncia a derechos superiores, constitucionales y supranacionales, que constituyen hitos en la lucha por la paz y la justicia a lo largo de toda la historia.

\footnotetext{
2 Este trabajo se ha realizado disfrutando de dos ayudas a la investigación: I + D: Las reformas procesales: un análisis comparado de la armonización como convergencia y remisión de los procesos civil y penal (DER 2010-15919) (subprograma JURI) Y: Cuestiones actuales de Derecho procesal. 2009-2013 (SGR 762)".

3 Un desarrollo pormenorizado de las mismas, sus causas y algunas de las ideas vertidas en este trabajo en ARMENTA-DEU, T. Sistemas procesales penales (La justicia penal en Europa y América), Marcial Pons, 2012, 316 p. (ISBN 978-84-9768-913-7).
} 


\section{La relevancia del cuerpo social y cultural en que se insertan las reformas}

No cabe olvidar que las reformas afectan y deben encajarse en un cuerpo cultural social y culturalmente complejo, heredero de una tradición histórica que incide, y no poco, en el resultado final, como se infiere claramente si se piensa con un poco de detenimiento en la tremendadiferencia que acarrea la arraigada creencia en la legitimación democrática, que fundamenta toda institución en los países del common law, en relación con la figura y función del fiscal en el proceso, por ejemplo, en contraste con la confianza en la legalidad y la seguridad jurídica, que empapa el sentimiento continental europeo, en relación con la negociación, pongamos por caso.

En este orden de cuestiones, por citar dos ejemplos españoles que ilustran perfectamente esta idea, los vaivenes en la Ley Orgánica reguladora de la responsabilidad penal de los menores y la intervención de las víctimas y sus familiares o el largo debate en torno a las restricciones de la acción populardeberían constituir un aviso para el legislador del futuro, al igual que, por acudir a otros ejemplos, consideraciones semejantes podrían derivarse de las anunciadas reformas de la fiscalía propuestas en Italia por el gobierno Berlusconi o las ya alcanzadas en Ecuador, previo referendum, restringiendo la independencia judicial.

\section{Los sistemas y el "debido proceso": una cuestión de pesos y contrapesos}

Admitiendo de inicio la inexistencia de un modelo perfecto la búsqueda del mejor de los posibles debe partir de alguna aclaración o y de encontrar el necesario equilibrio entre los elementos en un juego de pesos y contrapesos.

\section{Acusatorio y adversativo}

Entiendo necesario dejar claro el significado de los términos acusatorio, dispositivo y adversativo para que al menos utilicemos "nomen" con un significado equivalente; de otro modo toda discusión se convierte en un "diálogo de sordos".

Justicia acusatoria y justicia adversativa no son configuraciones idénticas, sino queatienden a planos diferentes.

El sistema acusatorio se sitúa en el plano de la necesidad de una acusación y con ello de la exigencia de imparcialidad.

El adversativo, por su parte, lo hace en el plano de la audiencia o contradicción.

El proceso acusatorio exige que alguien sostenga la acción, en tanto el adversativo la confrontación entre dos partes con igualdad de armas bajo la dirección de un tercero imparcial. 
En otras palabras, el sistema acusatorio enfoca sustancialmente las exigencias relativas a la acusación, a la imparcialidad que garantiza y al hecho de que el acusador no puede acusar, sin más, debiendo ofrecer evidencias suficientes de culpabilidad como para apreciar la existencia de una "causa probable". De ahí que la presunción de inocencia constituya un elemento esencial de la configuración acusatoria.

Y paralelamente, que toda investigación previa al juicio se limite a fundamentar la acusación, como justificación para iniciar un proceso, siempre y cuando nada de lo recabado constituya en teoría prueba de cargo. Exigencias que desde el punto de vista -esta vez del adversativo- acarrearían que una vez encomendada en exclusiva la acusación al fiscal o a la policía, siempre entendidas como partes, se reclame de nuevo la igualdad de armas y la necesidad del disclosure, exigencias cuya dificultad ponen en evidencia reformas como la italiana, ya que o bien no se quieren adoptar o hacerlo comporta un coste cuando mínimo cuestionable.

\section{El modelo de "debido proceso": ponderaciones y búsqueda de equilibrio}

A partir de que las variables citadas y otras imposibles de citar son tales que imposibilitan elaborar un "patrón" de proceso penal que encaje en todos los cuerpos sociales, culturales y políticos con idéntico efecto, sólo queda buscar aquellos elementos imprescindibles para que un proceso merezca el calificativo de "justo" o "debido". Y a qartir de ahí, buscar el necesario equilibrio entre los elementos que necesariamente aparecerán tensionando en direcciones opuestas.

En una primera aproximación cabe señalar que los elementos consistirían en equilibrar la inevitable tensión entre pares que tensionan en dirección contraria. Se trata de los siguientes en una relación no exhaustiva:

- la eficacia y las garantias,

- la fase instructora, su dirección y objetivos,

- el creciente incremento en la aplicación del principio de oportunidad,

- el papel de lavíctima en el proceso,

- la incidencia de los pactos internacionales y los tribunales supranacionales y,

- la justicia negociada y el abandono del proceso,

De no hacerlo así, los riesgos se centran en:

- la quiebra de la división de poderes,

- la privatización de la justicia penal, paralela a la publicitización del proceso civil,

- la vuelta a la autotutela (Argentina, Perú, como retroceso, pero países africanos y asiáticos como ejemplo no evolucionado). 


\section{Elementos en tensión: algunos ejemplos}

Varios factores empujan en diversos sentidos, no ya sólo entre los diferentes sistemas sino en el plano de los derechos, en muchas ocasiones en direcciones divergentes o incluso enfrentadas. Los ejemplos son múltiples:

- la preocupación por fortalecer los derechos del imputado exige observar formas que desaceleran el impulso de acciones penales y que pueden complicar la búsqueda de la verdad,

- preocupaciones pragmáticas requieren la simplificación de los procesos, haciendo preciso una vez más buscar el mejor equilibrio posible con otros objetivos, como preservar determinadas garantías, para no incurrir en una renuncia desproporcionada que a la postre pierda fundamento y probablemente provoque efectos contrarios o cuando menos no deseados.

Piénsese, por ejemplo, en la conjunción de los juicios rápidos, con la aplicación de soluciones consensuadas y la fuga hacia métodos no jurisdiccionales, fenómenos que aunque se suelen asociar a países donde rige un sistema adversativo,hoy en día se han extendido de tal forma que cualquier valoración exige abstraerse del modelo en cuestión.

Cualquiera de estos tres instrumentos, por separado, o adoptados en atención a situaciones específicas, puede resultar beneficioso, pero cuando las reformas se encaminan únicamente a la mayor amplitud de dichos mecanismos, y eso es en definitiva lo que puede ocurrir cuando se parte de diferencias entre pequeña y gran criminalidad, la renuncia termina afectando al propio proceso, a una garantía que no deberíamos olvidar se ha conseguido laboriosamente a través de los siglos.

\section{El ejemplo de la dialéctica acusatorio/inquisitivo adversativo/mixto}

Partiendo de las múltiples variantes de ejercicio de la acusación penal, las tensiones aparecen con independencia de la modalidad adoptada, como ha sucedido recientemente en Italia o en el Ecuador a la hora de fijar los límites de la independencia del acusador, sin que el régimen de monopolio rebaje aquellas per se, más bien al contrario.

La tendencia a la oficialidad que genera que la acusación quede encomendada a un único órgano, procura y satisface al adversativo, no cabe duda, ahora bien, no resulta una opción exenta de riesgos, ya que al cifrar una cuestión tan relevante como el ejercicio de la acción en una única mano, que además depende del ejecutivo,inclina la balanza hacia una acumulación de poderes, del ejecutivo e indirectamente del judicial, en la medida en que no llegará a ser juzgado ningún delito cuya acción no se ejercite a través del juicio (nullum crimen sine indicio).

Esta cuestión es la que ha situado en el "punto de mira" a la acción popular en España, no tanto como se afirma por su eventual utilización indebida, cuanto por constituir un obstáculo a la configuración claramente oficialista y controlada del ejercicio de la 
acción penal, olvidando su demostrada efectividad a la hora de contrarestarla inacción, justificada o no, del MF en la persecución de delitos que el poder público prefiere olvidar.

Por otra parte, ni la transición de las investigaciones judiciales a las fiscales incide sustancialmente en la estructura "inquisitiva" de los procesos, ni es correcto afirmar que la instrucción en manos de los fiscales evidencia una mayor preocupación por los derechos humanos.

La búsqueda de equilibrio resulta especialmente difícil si como es frecuente el modelo se acoge parcialmente rechazando medidas que son el lógico correlato de otras o que constituyen un factor esencial del mismo.

Resulta paradigmático en este sentido que la búsqueda del modelo adversativo no vaya acompañado delabandono del monopolio investigativo oficial y la autorización a los abogados defensores a llevar a cabo sus propias investigaciones, excepto en Italia, con las dificultades conocidas.

Claro que así se renunciará al control de la fase investigadora y en buena medida al del ejercicio de la acusación,pero claramente se alcanzaría una auténtica contienda entre partes,implicando un sistema equitativo para la revelación mutua de información pero un correlativoincremento de costos.

Más aún, cuando, como realmente sería fundamental para un modelo adversativo, se privara al juez del acceso a la información del expediente oficial de la investigación y la determinación de los hechos quedara en manos de las partes, convirtiendo a aquél en un auténtico evaluador de lo aportado por el acusador y el defensor y no en un buscador independiente de la verdad. ${ }^{4}$

A falta de un respuesta radical, probablemente inexistente, torna a surgir la necesidad de ponderar las ventajas que desde una perspectiva global, de derecho penal y procesal penal, avalan tan sustancial cambio en el sistema, sacrificando algunas de las conquistas fundamentales del Estado de Derecho desde el siglo XIX.

No se olvide, por otra parte, que la conjunción de determinadas medidas puede conducir a resultados que no eran los deseados, o peor aún, que lo son en una dirección no deseable.

\section{Los sistemas en la historia y actualidad: examen y crítica}

\section{Modelos adversativos}

Un modelo adversativo se estructura como una disputa entre partes, acusador y acusado, desarrollada ante un tercero, donde el juez actúa de manera pasiva. Un proceso

4 Es lo que Damaška denomina una "adaptación transformativa" mucho más real que la inmediatezy la necesidad de reproducir o producir la prueba en el juicio, como forma de minimizar el riesgo de que el juez que preside la investigación este familiarizado con el material investigador del expediente oficial. 
penal en el que las partes son dueñas de la contienda y deben impulsar el proceso con su actividad.

\section{A) Gran Bretaña}

Actualmente en Gran Bretaña la policía lleva todo el peso de la investigación, lo que permite cernir dudas sobre la efectiva separación entre investigación y acusación.

Organizada localmente goza de independencia funcional y disfruta de un amplio margen de libertad de criterio acerca de cuando y como iniciar el proceso penal.

La acusación es en nombre de la Corona, generalmente de la policía, y también, si así lo requiere, del Attorney General, del Director of Public Prosecutions o de la Crown Prosecution Service.

El control para verificar la admisibilidad de la acción penal se realiza a partir de la intervención del propio Crown Prosecution Service, correspondiendo al juez comprobar la existencia de elementos suficientes para proceder, así como que la actividad policial ha sido legal.

El juicio de acusación en Inglaterra, originariamente discrecional y atribuido a la policía, encuentra, desde la creación del Crown Prosecution Service, algunas limitaciones, ya que este último puede instar a la policía a adquirir más elementos de prueba o incluso puede desistir del ejercicio de la acción sin el consentimiento de aquella, ocupándose de la dirección técnica de la acusación obligatoriamente.

Sí existe, no obstante, un control político sobre los criterios de discrecionalidad en el ejercicio de la acción penal, vertiendo el juicio de acusación sobre su fundamento,tanto desde la perspectiva de sus posibilidades de éxito, cuanto de su eventual frustración por las actividades desarrolladas por la policía, si éstas son consideradas ilícitas.

B) Estados Unidos de Norteamerica

La primera consideración a este respecto debe partir de un hecho que los propiosautores reconocen: el modelo se aplica en realidad a menos de un 1,5-2\% de la criminalidad en los EEUU, lo que significa que la mirada se centra en poco mas que una ilusiónen su aplicación real.

Cuando se inquiere sobre las razones, la respuesta es unánime: resulta imposible resolver los problemas de criminalidad respetando el sistema, circunstancia que ha conducido al bargaining en sus diversas modalidades como método real en la persecución de los delitos en el país norteamericano.

Con todo, la doctrina insiste en que la institución clave en el proceso norteamericano es el jurado, tanto el civil como el penal, que sirven en EEUU de vía de comunicación idónea entre jueces y ciudadanos, trasmitiendo y haciendo compartir la idea de justicia. Las razones de su actual declive no pueden ser acometidas en detalle, pero una mera aproximación necesita de unas explicaciones previas, sobre todo en orden a puntualizar algunos datos en torno a los llamados ADR. 
Empezando por ésta última, el Gran Jurado fue considerado históricamente como una salvaguarda frente a persecuciones malintencionadas, según recoge la propia jurisprudencia estadounidense: "cumple (sic: el Gran Jurado) la inestimable función de situarse entre el acusador y el acusado al objeto de determinar si la acusación persigue un objetivo torticero.

De hecho, la V enmienda de la Constitución norteamericana exigía que solamente el gran jurado tuviera competencia para formular la acusación penal, y en dicha función se detectan atribuciones tan amplias que parecería ofrecer tintes inquisitivos. El Gran Jurado, era el único órgano que según el Bill of Rights tiene competencia para ejercitar la acción penal (V Enmienda) (McNeill v. Wisconsin, 501 U.S, 717, 181 (1991).

El jurado interviene como tercer control del ejercicio de la acción, una vez se han llevado a cabo las siguientes actuaciones:

$1^{a}$ ) investigaciónpolicial que determina los hechos,

$2^{a}$ ) arresto o detención del imputado previa orden judicial y donde se permite una llamada,

$3^{3}$ ) decisión de acusar (complaint) tras revisar las actuaciones judiciales del fiscal y la policía, que convierte al acusado en defendant, y debe ser revisado sin presencia de la defensa para determinar si existe probable cause.

Con carácter previo se han celebrado:

A) La primera comparecencia del acusado, antes de trascurridas 48 horas dela detención, para constatar su identidad, formular los cargos e informarle de sus derechos (a guardar silencio y a la asistencia letrada, sustancialmente), así como para determinar la fianza para la libertad provisional.

B) La preliminary hearing para comprobar, ya con contradicción, la suficiencia probatoria.

A partir de entonces, el jurado formado por de 16 a 23 jurados (Cortes Federales) revisa la acusación y el fiscal efectúa una propuesta de indictment, documento de acusación que sustituye al complaint y que debe someterse al jurado.

4⿳亠口冋口) Comparecencias

En la comparecencia del acusado (arraignment) una vez informado de los cargos y de la acusación formal, se manifiesta sobre culpabilidad o no culpabilidad (nolo contendere) como resultado de las conversaciones con el fiscal y las diversas modalidades del bargaining (deja de ser un sospechoso (suspect) y pasa a ser un acusado (defendant). ${ }^{5}$

5 Las pretrial motions constituyen una fase de alegaciones sobre la legalidad de ciertas acusaciones y la vulneración de derechos tras el discovery opresentación del caso desde el punto de vista de la otra parte y la exhibición (disclosure) de los testigos y otras pruebas por ambas partes, así como del resultado de peritajes oficiales. 
El principio general es que el acusado tiene derecho a un juicio público que sólo puederestringirse en atención al tipo de delito o a la necesidad de preservar la publicidad de la prueba. Derecho al que sólo cabe renunciar con el necesario acuerdo del prosecutor, a través de las diversas variantes de plea: en cualquier momento, mediante la interrupción del acusado ofreciendo una admisión de culpa (del indictement or information), o a través de guilty plea, que supone a su vez un acuerdo previo para e obviar cierto cargos o alcanzar una sentencia más benigna (plea bargaining).

Cabe destacar que frente a abusos iniciales en una negociación frecuentemente desigual, en muchos Estados, el desistimiento precisa del acuerdo judicial, en tanto en la mayoría de los supuestos corresponde al juez de la Corte dirigirse al acusado para comprobar su pleno conocimiento en torno a: que el acuerdo implica la renuncia a su derecho al juicio ante el jurado y al derecho a la contradicción con los testigos, a que se ha alcanzado con plenitud de conocimiento y libre voluntad, o lo que es lo mismo, que no ha sido coaccionado ni directa ni indirectamente, ni se la ha ofrecido otra recompensa o ventaja que la que forma parte del acuerdo, en sí mismo, así como que se es claramente consciente de las consecuencias de dicho acuerdo.

En el infrecuente supuesto en que se llegue al juicio, éste se inicia con la presentación de cargos y descargos, la prueba debe practicarse de forma oral y pública, sin incorporar la documentaciónque recoja resultados del pre trial, salvo tratarse de una declaración documentada y que el declarante deponga ante el jurado como testigo.

Paralelamente, la documentación de la declaración de los testigos en la preliminary hearing no puede incorporarse como prueba al juicio, salvo que resulte imposible que el testigo comparezca.

Finalmente, el acusado debe estar presente y podrá ser examinado, correspondiendo a su defensasiempre el alegato final.

El jurado debe pronunciarse sobre la culpabilidad si las pruebas de cargo sitúan su convicción sobre su culpabilidad beyond any reasonable doubt, correspondiendo la imposición de la pena a la fase pos trial, así como la existencia y procedencia de recursos contra el veredicto, que excluye siempre la insuficiencia probatoria.

\section{Notas comunes del sistema adversativo: paridad y contradicción como parámetros}

La nota común del adversativo es ser un juicio de partes en el que el juez y el jurado ostentan una posición pasiva, limitándose a decidir las cuestiones de hecho y derecho que le plantean las partes.

De ahí, que deban existir dos investigaciones separadas, la desarrollada por el fiscal y la policía, y la del imputado y su defensor, siendo cada parte dueña de su propia investigación y resultando ambas independientes, hasta el momento en que se tenga la obligación de desvelar los datos y medios probatorios obtenidos (disclosure). 
Existe asimismo acuerdo en centrar la esencialidad del modelo en las siguientes notas:

- en primer término,la iniciativa de las partes, tanto para accionar cuanto para probar,o lo que es lo mismo, la posición del juez absolutamente neutral y equidistante;

- en segundo término: el abandono de la búsqueda de la verdad como finalidad del proceso penal, es decir, la satisfacción procedente deaceptar como verdad plausible el resultado de la confrontación entre la aportación y práctica de la prueba por las partes, incluyendo los efectos derivados de la sporting theory;

- en tercer término: no utilizar al acusado como objeto de investigación y evitar a toda costa que una persona se vea sometida a una acusación infundada o a la llamada "pena de banquillo", mediante impedir que la prueba sólo pueda practicarse en el proceso y, finalmente;

- en último lugar, admitir como pruebas de cargo únicamente aquellas que se producen oralmente y ante el jurado, estando sometidas a examen cruzado característica ésta última que al menos en el plano teórico implica rechazar la admisibilidad de actuaciones efectuadas fuera del juicio, aunque estuvieran documentadas e incorporadas a un dossier y fueran leídas durante el juicio, práctica ésta última que no obstante admite la jurisprudencia norteamericana.

\section{Autocrítica del adversativo americano}

La crítica se centra en la percepción de aspectos inquisitoriales en el propio sistema, esto es, en detectar más defectos ajenos que virtudes propias.

Se alerta, en primer lugar, sobre la ausencia del deber del tribunal de comprobar la veracidad de los cargos de la acusación en el proceso, que no ha impedido, sino todo lo contrario, que el Congreso de los EEUU y el Tribunal Supremo amplíen su poder inquisitivo permitiendo averiguar la verdad mediante interceptaciones telefónicas, entradas y registro domiciliarios e incautaciones.

En segundo lugar, en la limitación del derecho a no autoincriminarse que acarrea la posición de la Corte Suprema norteamericana, cuando ha aceptado leyes que exigen al acusado informar antes del juicio de la utilización de defensas positivas, como una coartada o de alegar la inimputabilidad.

En tercer lugar, en torno a la fase de investigación ante el Gran Jurado, cuando se permite que éste último puede obligar a los testigos a declarar en secreto sin alegar previamente la relevancia del testimonio, que el testigo llamado a declarar no tenga derecho a estar asistido por abogado y que todos cuantos participan están sometidos al deber de reserva,o que el futuro acusado no presencie los actos de investigación ni conozca sus resultados, como que tampoco pueda presentar medios de prueba propios o cuestionar el fundamento de la acusación (indictment). 
Se objeta incluso, que a diferencia del fiscal instructor europeo, el fiscal ante el "Gran Jurado" no tiene obligación de presentar la prueba exculpatoria aunque le conste su existencia y como no, el plea bargaining, que ya desde sus inicios fue rechazado por lasdiferentes Cortes, negando autoridad al prosecutor para alcanzar compromisos, por violar los principios legales establecidos legalmente, y cuya aceptación obedeció a la concurrencia de diversos intereses, especialmente ser el instrumento a través del cual se resuelve el98\% de los casos con alta satisfacción de los diferentes partícipes en el proceso.

Pero, además, porque toda resolución obtenida mediante guilty plea niega el adversativo por esencia y conduce a mayores presiones del prosecutor cuanto más débil es la acusación y mayor es el riesgo de absolución en el proceso, sin olvidar, finalmente,la renuncia forzada al privilege against self-incrimination y otros derechos constitucionales, como el derecho a ser juzgado por un jurado y la crítica reiterada a la oscuridad de las negociaciones que preceden al acuerdo, cuando no a las prácticas criticables del acusador. Tales como las siguientes:

- acudir al interrogatorio del acusado e intentar persuadirle directa o indirectamente de que acepte un acuerdo o limitar sus derechos a través de declararse culpable.

Con todo, la desigualdad constituye el verdadero "talón de Aquiles" del sistema. De hecho, aun tratándose de datos de 1992, se dedicaron 97.500.000 U\$S a la investigación de fiscales y policías, y sólo un $2 \%$ de este presupuesto se dedicó a la defensa de indigentes que constituye, sin embargo, un $80 \%$ de los casos. Y aunque algún autor argumente que esta desigualdad sería subsanable mediante una decisión política que invirtiera las cantidades, la realidad - siempre terca - se empeña en demostrar lo contrario.

\section{Modelos mixtos: crítica y precisiones en torno a los erróneamente denominados sistemas inquisitivos. Rechazo de descalificaciones apriorísticas}

A) El sistema continental (sistema mixto, o de acusación oficial) o por decirlo mejor, el original sistema acusatorio ha sido objeto reiterado de dos críticas específicas: la falta de imparcialidad del órgano encargado de la investigación, y tratar a los ciudadanos como objetos de investigación en lugar de como sujetos de derechos.

La primera carencia se ha afrontado mediante la distinción entre funciones investigadoras a cargo del fiscal y decisorias a cargo del juez o previendo que el juez que instruye no juzgará.

La segunda, se ha encarado reconociendo al imputado una serie de derechos más amplios en el juicio y menores en la investigación (informar de la imputación; poner a su disposición el objeto y resultado de la investigación; solicitar medidas etc.). 
B) Desde una perspectiva adversativa lo que preocupa es preservar la absoluta neutralidad del juez como efecto de la dialéctica de confrontación, aún a costa de que a falta de buenos mecanismos que salvaguarden el derecho de defensa, la desigualdad resultante es enorme y tremendamente injusta.

Desde la óptica acusatoria, por su parte, al incidir en fundamentar suficientemente el ejercicio de la acción antes de actuar, se arrostra el riesgo de contemplar una fase que puede suponer aquello que se pretende evitar, esto es, utilizar al acusado como fuente de prueba y generar la llamada "pena de banquillo", especialmente si el investigado después no resulta acusado.

Obsérvese no obstante que tanto en uno como en otro se busca preservar la imparcialidad del juez, parámetro que hoy en día es asimismo determinante en los procesos europeos y que cabe formular así:

- quien acusa no puede juzgar, y de ahí que no puede haber proceso si no hay acusación y;

- la acusación ha de ser formulada por persona distinta de quien debe juzgar, y que no puede condenarse ni por hechos distintos de los acusados ni a persona diferente de la acusada;

- el juez no puede tener facultades de dirección material, exigencia ésta última que implica a su vez, que la aportación de hechos al proceso no forma parte de las facultades de dirección sino del principio acusatorio, y quela dirección material se refiere a la prueba de los hechos aportados por el acusador, en tanto el reconocimiento al juzgador de facultades para contribuir con las partes a la comprobación de la verdad de tales hechos no atenta a su imparcialidad.

C) Parece que los reproches formuladoscontra cualquiera de los procesos de los países continentales europeos - reproches so pretexto de "inquisitoriedad" - no conducen a ningún lugar y sobre todo no provienen de una posición especialmente legitimada, al igual que sucedería si fuera al revés.

Y no porque no exista fundamento dogmático alguno, sino porque en tal juicio se prescinde de las diversas configuraciones de la fase de investigación y las garantías preservadas en los distintos ordenamientos que pueden conducir a una mejor valoración en cuanto implican la intervención judicial (garantía jurisdiccional) frente a la configuración administrativa imperante en GB, por ejemplo.

La crítica, que pudo tener fundamento en algún momento histórico, y no sólorespecto de los países de tradición continental, resulta hoy en día simplemente carente de fundamentos, olvidando los importantes logros alcanzados, así como que ni uno ni otroexistieron en estado puro ni perviven así, y que finalmente como se ha podido comprobarse detectan "notas inquisitivas" a ambos lados del Atlántico.

Sí existen, no obstante, elementos que pueden fundar una crítica y consecuente necesidad de reformulación en los procesos mixtos: 
- la propia estructura de la instrucción o investigación de los delitos;

- propiciar la llamada "pena de banquillo";

- permitir la condena en atención a la declaración delimputado en la instrucción y la intervención judicial en el juicio en materia probatoria.

El objeto de la crítica converge, por otra parte, con reproches provenientes del propio sistema continental que mira al adversativo como modelo, o que, contradictoriamente, persigue una creciente oficialización de determinados aspectos del proceso, como la dirección de la investigación y el ejercicio y sostén de la acción penal.

D) Valoraciones críticas cruzadas

Cuando acudimos a un punto de vista más integrador, el modelo de civil law, continental o mixto, tiende a ser un modelo de investigación oficial más que un modelo "de disputa", al igual que el modelo mixto tiende a una estructura jerárquica en tanto el modelo del common law adopta otra más "coordinada".

Cabe admitir incluso que dicho modelo arroje sombras sobre la utilización del acusado como fuente de información o las dudas sobre la imparcialidad de los órganos oficiales, del juez, ciertamente, pero también del acusador si no se le configura como verdadera parte.

Ahora bien, desde otra perspectiva, el modelo adversativo presenta características difíciles de aceptar,

- una desigualdad difícilmente tolerable,

- la configuración administrativa de la fase de investigación y,

- la incontestable realidad de un modelo "en el cielo de los conceptos jurídicos", alejado por completo de la realidad del que llega a afirmarse que tiende a garantizar los derechos del imputado en la medida en que resulta ineficaz y sólo resulta eficaz cuando se aleja del modelo adversativo mancillando dichas garantías.

Circunstancia que por otra parte también puede detectarse en los procedimientos mixtos como se pone de relieve con la negociación o los diversos mecanismos aceleradores adoptados en Europa e Iberoamérica, la mayor parte a costa de la renuncia al derecho al proceso, a la práctica de la prueba o a otros derechos, incluidos en la conformación del "proceso debido".

\section{Las fórmulas negociadoras: el verdadero tiro en la línea de flotación}

Si existieran unas estadísticas mundiales nos asombraría - o quizás no tanto - el altísimo número de soluciones consensuadas de procesos penales. 
No quiero entrar ahora en un análisis pormenorizado, aunque sí recordar algunos aspectos como los siguientes:

- La negociación se introdujo y a crecido a partir del progresivo retroceso en la aplicación del principio de legalidad, convirtiéndose en la actualidad en la puerta de bienvenida del abandono del proceso hacia métodos extrajudiciales.

La posibilidad de negociación conducirían el modelo de investigación oficial hacia un modelo adversativo en mucha mayor medida quela reiterada discusión sobre elfiscal instructor, ya que el modelo de la disputa contempla el proceso penal como un enfrentamiento entre dos partes y acoge de manera naturalel poder negociar sobre las consecuencias del delito poniéndose total o parcialmente de acuerdo.

- Los beneficioso efectos para los protagonistas del proceso.Para el acusado, que evita el proceso o incluso la propia acusación si el acuerdo es previo y tiene oportunidad de reconocer su culpa y deiniciar la rehabilitación, para el MP y el juez, que obtienen una pronta resolución economizando medios a la justicia y obteniendo un resultado siempre positivo desde el punto de vista de la resolución condenatoria. Ypara elabogado que ofrece a su cliente una resolución siempre aparentemente satisfactoria y un resultado más acorde con su propia agenda de trabajo.

- La resolución mediante consenso resulta una forma más rápida y económica de resolución del conflicto, que evita simultáneamente impugnaciones, acelerando aún más la resolución final, pornacer de un acuerdo entre quienes estarían legitimados para recurrir.

- La paradoja causal: el incremento del derecho de defensa ha conducido al barganining, constituyendo en buena medida "la causa del mal causado" porque dicho desarrollo ha convertido el proceso enexcesivamente largo y costoso, hasta hacer de la necesidad su mayor virtud, ya sea por las dificultades probatorias, ya por el incremento de procesos y garantías y la imposibilidad de resolverlos todos.

- Argumento funcional: el alto número de guilty pleas se interpreta como elemento imprescindible para que la justicia penal funcione, de manera que pese a suponer la renuncia a un derecho tan esencialal sistema adversativo como el derecho de defensa, se consiente, al contribuir a que éste se mantenga, por así decirlo, en los niveles aceptables de funcionamiento. O como afirma la jurisprudencia norteamericana, sobreentendiendo, que si todos los imputados buscaran el ejercicio de sus derechos, el sistema "saltaría", lo que propicia que la renuncia de muchos permita cumplir a unos pocos con las garantías que le concede la Constitución.

Con todo, las conocidas en Europa como negociaciones ("conformidades", "absprache" "pattegiamento" etc.) no son en realidad una característica propia de ningún modelo, sino 
más bien constituyen diversas variantes de renuncia a las diversas garantías inherentes al proceso en cualquiera de los sistemas de referencia, ya sea la Confrotation and cross-examination, o el "derecho aser juzgado por el Jurado", en el adversativo,o el derecho al proceso o a la prueba, en el mixto. Habiendo obligado por otra parte a una reelaboración, cuando no deconstrucción de categorías como "la obligatoriedad de ejercitar la acción penal" (Italia); la participación de la víctima (quien puede resultar un obstáculo, reconduciéndola a una perceptora de indemnización por los perjuicios derivados de la comisión del delito); o la búsqueda de la verdad que debe abandonar ciertamente la verdad histórica y recomponer el deber de su búsqueda.

Al final cabe preguntarse: si es inevitable y si resulta aceptable la renuncia al derecho que conforman "un proceso justo" o"el debido proceso".

\section{Recapitulación sobre las cuestiones que deben valorarse y contrapesarse en toda reforma (una selección)}

Entre otros que podrían ilustrar los peligros citados me referiré a algunos tan evidentes como frecuentemente ignorados.

$1^{a}$ ) Dirección de la investigación

Que dirija la investigación el MF no resulta en sí mismo algo rechazable, siempre y cuando, claro está, se trate de un órgano con las necesarias garantías de independencia.

Su actuación visualiza la separación de las funciones acusadora y enjuiciadora, pero presenta varias dudas: si cabe exigir imparcialidad semejante entre investigación y enjuiciamiento y si requiereincorporar un órgano como el Juez de Garantías para no quebrar el presupuesto de jurisdiccionalidaden múltiples actuaciones a lo largo de la investigación, por no reiterar que no resulta el elemento clave para calificar o no un sistema de inquisitivo, o en todo caso, en menor medida que utilizar al acusado como fuente de información en la primera fase del proceso penal.

Riesgo, que la policía reclame la investigación (ej. Brasil, recientemente, Alemania o incluso en España)

\section{$2^{\underline{a}}$ ) Incremento del principio de oportunidad}

La adopción de las múltiples modalidades de principio de oportunidad resultan justificables cuando concurren determinadas circunstancias, y entre ellas desde luego, la necesidad de obtener una más pronta justicia.

Ahora bien, resulta asimismo incuestionable quemuchos de tales objetivos se alcanzarían a través de otros medios como incrementar el número de juzgados (o distribuir mejor los existentes) o despenalizar determinadas conductas, lo que de paso ayudaría al viejo sueño del derecho penal como ultima ratio. 
Y si estos medios no resultan los adecuados, la atribución de determinados márgenes de discrecionalidad o incluso de toda la discrecionalidad como en Francia, puede aceptarse, pero no incondicionalmente, no cuando simultáneamente se reduce al juez a un papel de mero espectador y desaparece cualquier control sobre el ejercicio de la acción, que esa es precisamente la discrecionalidad,

porque en tal caso, el acopio en una sola mano, más aún si dependen del ejecutivo, del poder de acusar, siendo ésta la única forma de realizar el derecho penal (nulla poena sine iudicium) aparece como un poder formidable. El recurrente protagonismo de la fiscalía en todas las reformas no parece refutar esta impresión.

\section{$3^{\circ}$ ) La posición de la víctima}

La posición de la víctima, regulada como titular únicamente de una pretensión indemnizatoria, posición que debe ser objeto de ponderación y equilibrio con la tendencia al monopolio en el ejercicio de la acción penal, que corresponde a la estructura bipolar del adversary system, y a que se atribuya al MF la iniciativa y las cargas procesales, relegando al juez a estrictas funciones de garantía y en su caso de dirección procesal.

Cuestión que por otra parte se corresponde con que el MF ostente una verdadera posición de parte, pero que,precisamente por igual motivo, permite que en la percepción norteamericana se detecten indicios de inquisitoriedad, cuando el juez abandona aquella posición para intervenir en el proceso en aras a mejorar su desarrollo, como sucede en los tribunales ad hoc o para salvaguardar algunos derechos, como acontece en los diversos tipos de bargaining.

$\left.4^{\mathrm{a}}\right)$ La existencia de legislaciones y tribunales supranacionales

No cabe echar en saco roto, además, la existencia de legislaciones supranacionales como es el caso de la normativa de la UE y por la incidencia de los tribunales supranacionales que obliga a jueces provenientes de uno y otro modelo a resolver conjuntamente sentados en el mismo tribunal.

Que los diferentes Estados asumieran un elenco de derechos comúnmente aceptados que operaren como "mínimo común denominador" de cualquier modelo, sin perjuicio, para ser realistas, de encontrar un punto de encuentro con los límites que marcan, de un lado, las peculiaridades que pudieran existir en los diferentes países o que provengan de una mayor protección, y de otro lado, los límites de las políticas públicas nacionales que corresponde fijar a aquellos.

Y unido a ello, que aceptar dicho parámetro implicaría constreñir la valoración de dichos derechos en un doble sentido positivo y negativos, es decir, ciñendo la aceptación al ámbito de los mismos pero sirviendo asimismo para denegar su aplicación, cuando el círculo interno del ordenamiento al que quiera aplicarse lo rechace por constituir una 
minoración del ámbito de tutela interno, en virtud de la "cláusula de progresividad" o "cláusula de no regresión".

$5^{\text {a }}$ La realidad histórica, social y política en que se insertan las reformas

Todo sin olvidar, que ni las reformas ni las importaciones comportan efectos taumatúrgicos como podría deducirse de la lectura de algún texto legal introductorio. Incorporar determinadas instituciones que representan o se adecuan mejor a un sistema adversativo, piénsese en el plea bargaining, por ejemplo, no convierte el sistema que lo adopta en más adversativo.

La explicación es bien sencilla, cada ordenamiento acoge la figura de una manera específica, propia, conduciendo en su conjunto, más que a una "americanización" o "adversativización" a una fragmentación.

La incorporación de las formas de negociación en los ordenamientos europeos no han supuesto una conversión del proceso en un "proceso de partes", algo esencial al adversativo, aunque sí ha obligado a una revisión de las teorías sobre la búsqueda de la verdad en materia probatoria.

Trasladar una institución no se hace "en el vacío" sino en un conjunto de instituciones y de prácticas jurídicas que modifican frecuentemente el resultado, al margen de la capacidad transformativa en el tiempo que dicha traslación comporte.

Por no mencionar otro aspecto trascendental, cual es que dos sistemas de procesos penales no son sólo una forma de resolver un conflicto o de distribuir funciones entre una serie de sujetos, sino más fundamentalmente formas de concebir algo tan arraigado en la cultura de un país como la administración de justicia, que a su vez hunde sus raíces en el devenir histórico y la conformación de la sociedad(Damaska: la música del derecho cambia, por así decirlo, cuando los instrumentos y sus intérpretes ya no son los mismos).

Los ejemplos serían innumerables, pero uno destaca por su relevancia: el profundo arraigo de la confianza en la legitimación democrática en la sociedad norteamericana, que sólo resulta equiparable con el relativo a la igualdad ante la ley en la historia y cultura continental europea, basado, no se olvide, en un principio de legalidad en la actualidad en franca retirada.

La incidencia de esta diversidad es un espejo inigualable para advertir como determinadas traslaciones comportan un alto riesgo en su efectiva asimilación en el sistema receptor, tal como se ha puesto de manifiesto en el caso de la reforma del proceso penal italiana dando pie a comentarios sobre el profundo compromiso de los sistemas de justicia europeos con la idea de brindar el mismo trato a los acusados, circunstancia que hace "dificilmente digerible" algo perfectamente posible en USA: que dos acusados puedan terminar acusados por delitos diferentes en atención a evidencias semejantes, como sucedió, entre otros casos en Bordenkircher $v$. Hayes, en el que el acusado fue acusado por un delito castigado con pena de hasta 10 años, el fiscal le ofreció una declaración de culpabilidad por cinco años, advirtiéndole simultáneamente que si 
insistía podía acusarle como delincuente habitual por sus antecedentes con hasta cadena perpetua. Como se ha definido gráficamente: "Para una mente continental Hayes es una pesadilla. Efectivamente, en el ámbito social y jurídicoangloamericano la ausencia de imparcialidad es un óbice insuperable, en la misma medida que la desigualdad lo es en la tradición jurídica de los países continentales de Europa.

\section{A modo de reflexión final}

Cohonestar esta y otras divergencias constituye el verdadero reto de las reformas para que puedanincorporarse al sistema jurídico, se llame como se llame, sin ocasionar desajustes o peor aún quiebras insuperables en el mismo.

A tal efecto, deben preservarse la historia y la cultura jurídica profundamente arraigada en cada país, donde en último término arraiga la confianza ciudadana que sirve de soporte a la "regulación legal".

Riesgos que se perciben en un mundo globalizado, donde cada vez los problemas son mas comunes y la necesidad de "aprender en cabeza ajena" más imperativo y donde - aún cuando resulta del todo imposible extenderme más - no debo dejar de advertir sobre el innegable peligro de la privatización de la justicia, cuando menos por dos razones: (a) el incremento desenfrenado de mecanismos negociadores en el proceso penal y el "canto de sirena" en el que puede acabar convirtiéndose los reclamos de una justicia más rápida e inmediata, como valor preponderante o incluso único; y (b) la huída del proceso que la historia y situaciones actuales evidencian que conducen a unretorno de la autotutela.

\section{Bibliografia de consulta}

AMODIO, E. The Accusatorial System Lost and Regained: Reforming Criminal Procedure in Italy. In: Criminal Justice between Crime Control and Due Process (Convergence and Divergence in Criminal Procedure Systems. Max-Planck-Institut für Auslandisches un internationals Strafrecht, Band, 101, 2004.

ARMENTA-DEU,T: Principio acusatorio y derecho penal, Bosch, 1995.

. La reforma del proceso penal: principios irrenunciables y opciones de política criminal, en Poder Judicial, nº 58, 2000.

. Sistemas procesales penales (La justicia penal en Europa y América). Marcial Pons, 2012, 316 p. (ISBN 978-84-9768-913-7).

AYALA CORAO, C. M. Las consecuencias de la jerarquía constitucional de los tratados relativos a derechos humanos. In: "La Constitución de 1978 y el constitucionalismo iberoamericano"/coord. por Francisco Fernández Segado, 2003, ISBN 84-259-1250-4.

BRADLEY, Craig $M$. The emerging international consensus as to criminal procedure rules”. 14 Michigan.J.Int'l L, 171-221, 1992-1993. 
BURNS, R. P. The Death of the American Trial. The University of Chicago Press, 2009.

DAMAŠKA, M. R. Aspectos globales de la reforma del proceso penal. In: Reformas de la Justicia Penal en las Américas (Fudación para el Debido Proceso Legal, 1999).

. The Faces of Justice and State Authority: A Comparative Approach to the Legal Process. New Haven, Yale University Press, 1986.

. The Uncertain Fate of Evidentiary Transplants: Anglo-American and Continental Experiments, 45 Am.J.Comp.L. 839-852, 840, 1997.

. Mischief of Plea Bargaining and Sentencing. Criminal Law Review, 895-910, 2000.

. Negotiated Justice in International Criminal Courts. 2 J.Int'l Crim.Just, 2009.

EISENSTEIN, J. Criminal Courts and bureaucratic justice: concessions and consensus in the guilty plea process, 76. The Journal of Criminal Law and Criminology, 1985, p. 1106.

FINE, R. A. Plea bargaining; an unnecessary evil, 70. Marquette Law Review 1987.

FISHER, G. Plea bargaining's triumph, 109, 857, 897YlJ, 2000.

FISS, Owen. Against Settlement. Yale Law Journal, nº 93.

GALANTER, M. The Vanishing Trial: An Examination of Trial and Related Matters in Federal and States Courts. Journal of Empirical Legal Studies Volume 1, Issue 3, 459-570, November 2004.

. A world without trials? J. Disp. Resol. 7, 2006.

LANGBEIN, J. H. The Origins of Adversary Criminal. Oxford, 2003.

LANGER, M. The rise of managerial judging in International criminal law. 53 The American Journal of Comparative Law, 835-909, nำ 14, 2005.

NOTE. Guilty Plea Bargaining: Compromises by Prosecutors to secure guilty pleas. 112 U.Pa.L.R.,1964.

. The Unconstitutionality of Plea Bargaining. 83 Harv. L.R., 1970, p. 13.

PIZZI, William T.; MONTAGNA, M. The battle to establish an adversarial trial system in Italy. Michigan Journal of International Law, vol. 25, 2004.

. Sentencing in the USA: An Inquisitorial Soul in an Adversarial Body. In: Crime, Procedure and Evidence in a Comparative and International Context 65,66 (John Jackson, Máximo Langer\&Peter Tillers ed), (2008).

SILVESTRI, E. Observaciones en materia de instrumentos alternativos para la resolución de controvérsias. Jueces para la democracia, nํㅜ 37, marzo 2000, p. 47 ss.

SKALNSKY, D.; YEAZELL, S. C. Anti-Inquisitorialism. Harvard Law Review, 122, 1684, 2008.

STITH, K. The Arc of Pendulum: Judges, Prosecutors, and the Exercise of Discretion. 117 The Yale Law Jounal, 2007-2008. 